\title{
Analysing The Temporal Pattern Of Crime Hotspots In South Yorkshire, United Kingdom
}

\author{
Hannatu Abdullahi \\ Department of Geography, \\ Kaduna State University, Kaduna, Nigeria \\ Idowu Innocent Abbas \\ Department of Geography, \\ Kaduna State University, Kaduna, Nigeria
}

\begin{abstract}
Visualizing the temporal pattern of crime hot spots supports the police authority in allocating resources, tactical planning, better management and decision making processes. This paper aimed at identifying temporal pattern of selected crime types (Antisocial behaviour (ASB), Vehicle crime and violent crime) in South Yorkshire, United Kingdom (UK).The study analysed 2011 South Yorkshire Police recorded crime data using statistical based method (graphical display) in Microsoft excel to identify monthly, seasonal pattern and trends of each crime type. Visual inspection from the temporal pattern of each crime type hot spot (figure 1 to 6) shows relationship between each crime type and months or seasons of the year. Result of the study reveals that autumn 2011 recorded the highest rates of violent crime and Spring 2011 had the lowest rates (figure 6).Finding of the research depicts that vehicle crime were higher in autumn and lower in spring 2011 (figure 4). July 2011 had the highest rates of ASB rates while December 2011 displayed lowest rates in figure 1.Monthly trend of crime in 2011 indicates (figure 5) that March 2011 had the highest rates of violent crime while September had the lowest rates. An interesting pattern in monthly violent crime was shown in figure 5 , as $\mathrm{R} 2$ value of 0.67 which reveals strong positive correlation between of the months of the year while $\mathrm{R} 2$ value of 0.3967 indicates weak correlation in seasonal trend of violent crime (figure 6). Rates of vehicle crime were higher in January 2011 and lower in April 2011 (figure 3). Monthly pattern of vehicle shows R2 value of 0.01048 in figure 3 shows no correlation between vehicle crime and the months of the year while figure 4 displays a remarkable pattern with $R 2$ value of 0.75 that indicates strong positive correlation between the seasons and vehicle crime. Interestingly, an examination from the $R^{2}$ of ASB temporal hot spots shows (figure 1 to 2), $R 2$ of 0.00112 shows that no correlation exists between ASB hot spots and the months while strong positive exist between the seasons with $R^{2}$ value of 0.7392 .
\end{abstract}

Keywords: Temporal, Pattern, Crime, Hotspots

\section{INTRODUCTION}

Criminal event occurs in a specific location and at a particular time. Space and time are key in analysing and understanding pattern of crime hot spots and how it can be tackled (Chainey and Ratcliffe, (2). Various models of crimes like the Place, street and opportunity theory have underscored numerous levels of crime and its distributional pattern. The place theory studies crimes at lowest geographic unit such as addresses, street corners or other minor places while street theory observes crime that takes place on stretched places like segment, blocks and pathways (Eck et al, (4).Neighbourhood concept considers crime concentration at a higher level which relates crime incidence with population density (Harries, (6).According to crime 
pattern theory people have a tendency of commit crimes in places they frequently visits and search for crime opportunities that are unevenly distributed across the space and time

Crime analysis entails examining spatial, temporal and sociodemographic elements in order to identify crime pattern, which would support law enforcement agency in criminal apprehension and other tactical crime reduction strategies (Santos, 2012). The main benefit of crime analysis is "to assist the police in criminal apprehension and evaluation" (Santos, (11).Previous studies (Evan and Fletcher (5); Takagi et al, (12) have shown that rising level of crime events are posing community risk and challenges in the UK. Growing number of studies (LeBeau (8), Brunsdon et al, (1);Takagi et al, (12), Harries (6); Nelson et al (9)) have analysed spatial pattern of crime hotspot in the study area but temporal pattern of crime has received little interest despite its enormous benefits in modern policing. There is need for further investigations on temporal pattern of crime hot spots in the study area for further crime reduction. Understanding temporal pattern of crime hot spots will not aid policing agency in criminal apprehension and evaluation but identifying the best time to allocate suitable resources .LeBeau (8) observed correction between crime and weather and finding of their study revealed that violent crime has strong relationship with weather as rates violent crime were high in summer than winter. This study aimed at analysing temporal pattern hot spots of each type (violent, vehicle and antisocial behaviour (ASB) in South Yorkshire,United Kingdom (UK). Key objective of study was to visualise crime hot spots temporal based on months and season of the year.

\section{MATERIALS AND METHOD}

Recorded crime data for 2011 were obtained from the South Yorkshire Police. The crime data were analysed using statistical based method (graphical display) in Microsoft excel. The recorded crime data were classified based on time of occurrence as month and season of the year for each crime type using graphical display in Microsoft excel,. Santos (11) revealed that crime analysts adopt numerous techniques in analysing temporal pattern of crime. These methods include analysis by time of the day, days of the week, and months of the year and seasons of the year (Santo, (11).This rationalised the choice statistical based technique for analysing temporal pattern of each crime type. Numerous earlier studies (Nelson et al (9); Ratcliffe; (10) had consistently applied statistical based method in analysing temporal pattern of crime hot spots. Cohen (3) studied link between crime and weather using statistical method. Result of their studies indicates statistical method excellent and one of the robust techniques for analysing temporal pattern of crime hot spot.

\section{RESULT}

The result of the study is as shown below. Figures 1 to 6 below show result of temporal pattern of crime hotspot by month and season of the year using statistical method in Microsoft excel. 


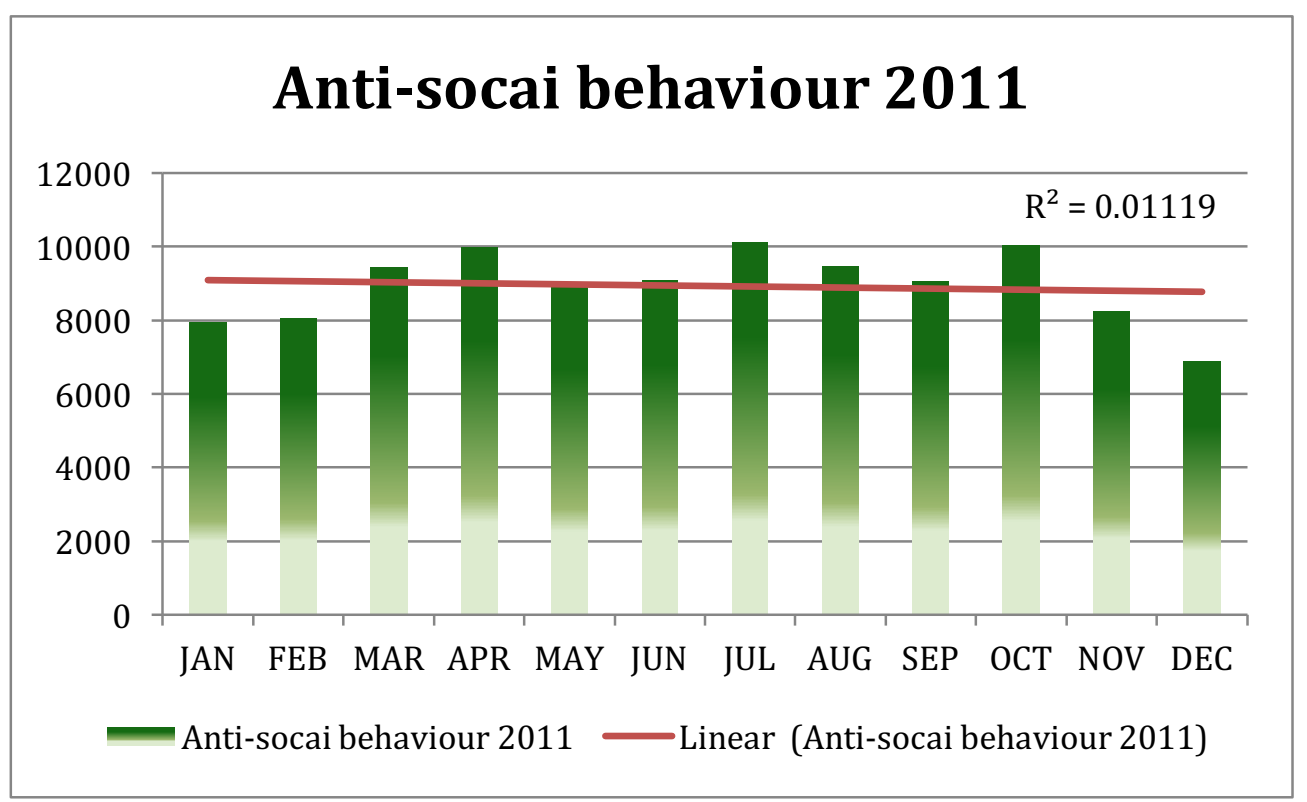

Mean=8928.16 and standard deviation $=985.69$

Figure 1 monthly pattern of ASB, source (South Yorkshire police, 2011)

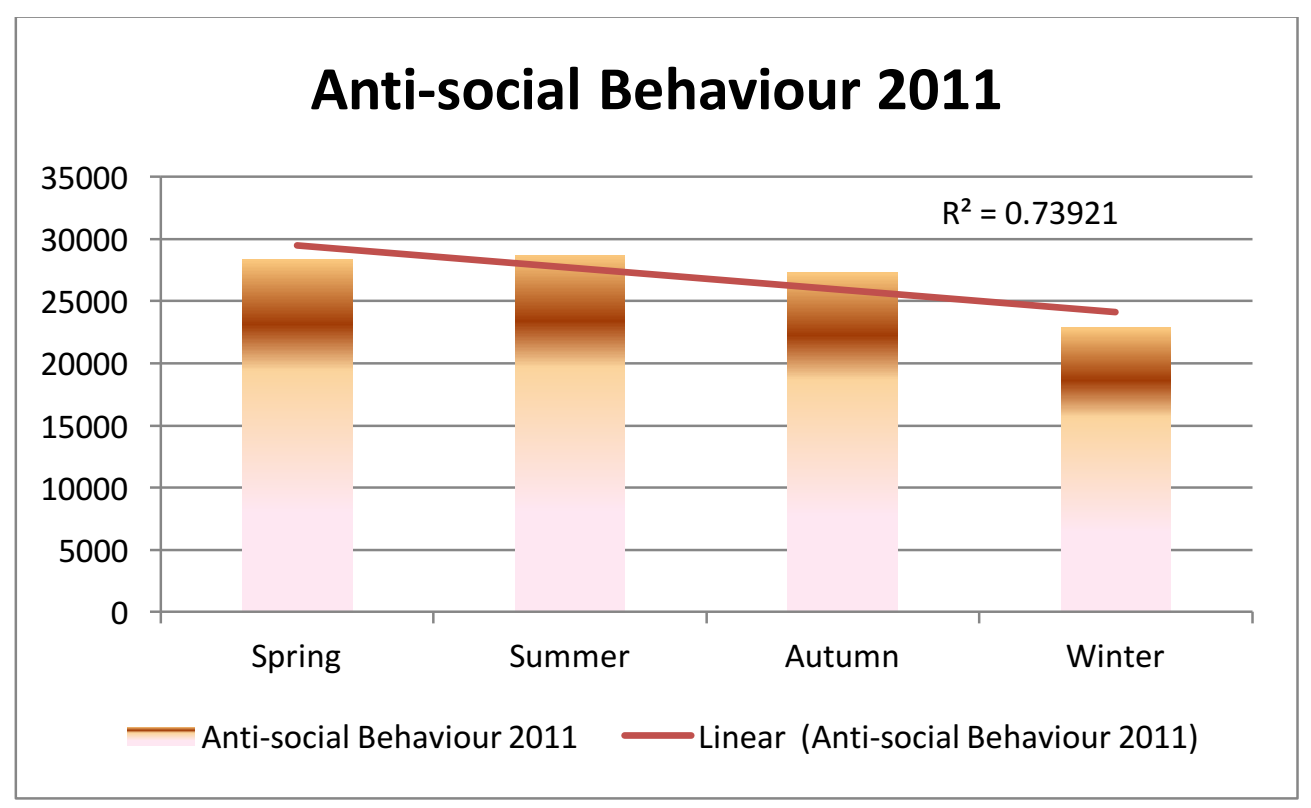

Mean $=26784.5$, standard deviation $=2321.9$

Figure 2 seasonal pattern of ASB in the study area; source (South Yorkshire Police, 2011)

Figure 1 and 2 show temporal pattern of ASB by both seasons and months. Looking at the graphs (figure 1 and 2), it can be observed that the month of July and summer display high rates of ASB while the December and winter display the lowest rates. Interestingly, an examination from the $\mathrm{R}^{2}$ (figure 1-2), $\mathrm{R} 2$ of 0.00112 shows that no correlation exists between the months while strong positive exist between the seasons with $\mathrm{R}^{2}$ value of 0.7392 . 


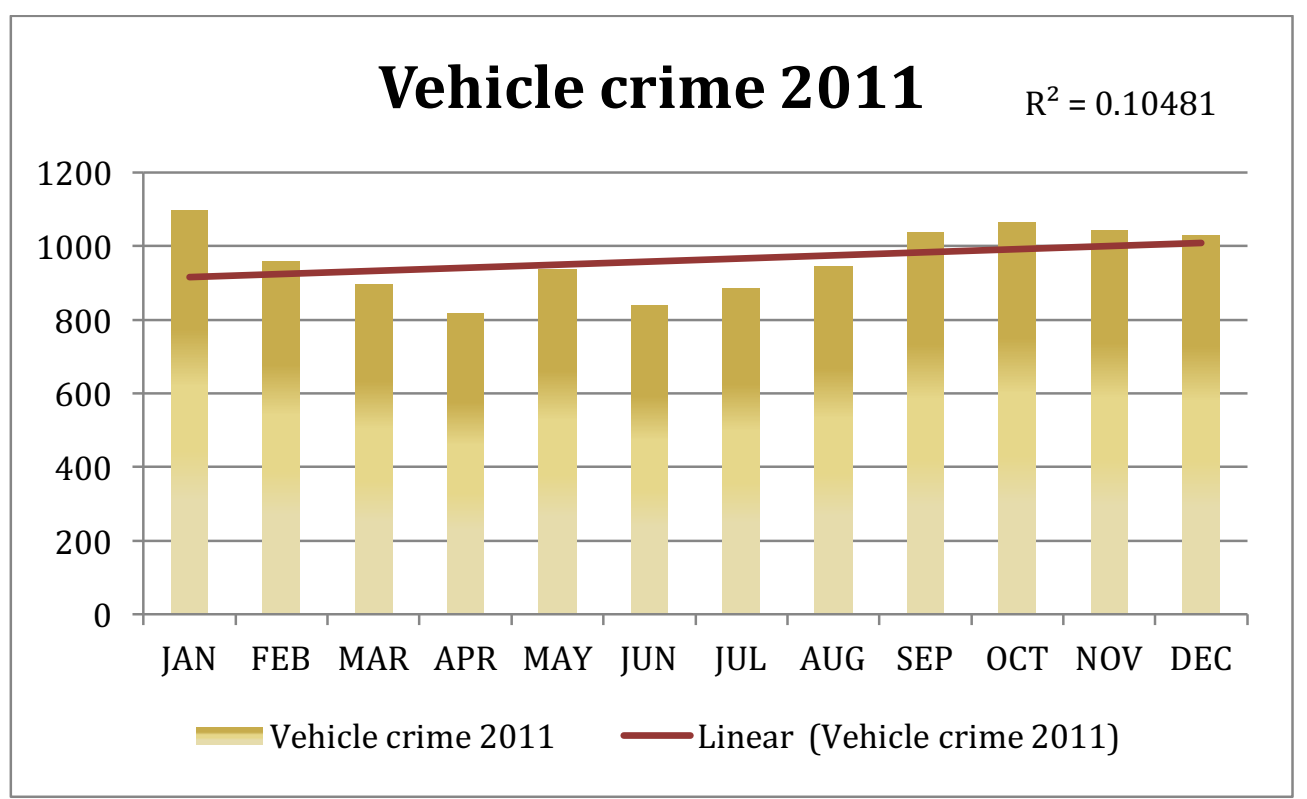

Mean $=961.83$, standard deviation $=92.28$

Figure 3 monthly pattern of vehicle crime, source (South Yorkshire police, 2011)

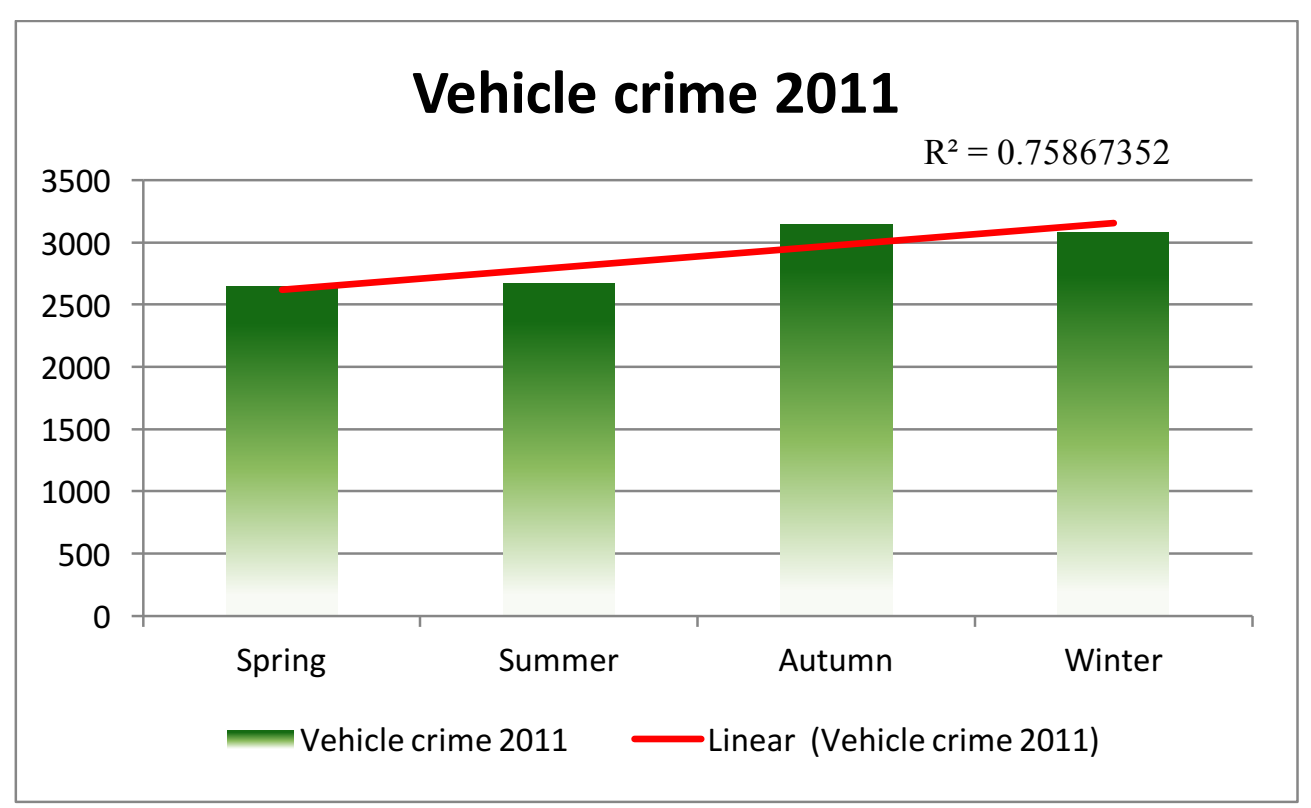

Mean $=28885.5$, standard deviation $=265.01$

Figure 4 seasonal pattern of vehicle crime in the study area; source (South Yorkshire Police)

Figure 3 and 4 display temporal pattern of vehicle crime. The month of January and autumn shows of vehicle crime while the lowest rates were displayed in April and summer (figure 3-4). $\mathrm{R}^{2}$ value of 0.01048 in figure 3 shows no correlation between the months of the year in vehicle crime while figure 4 displays a remarkable pattern with $\mathrm{R}^{2}$ value of 0.75 that indicates strong positive correlation between the seasons in vehicle crime. 


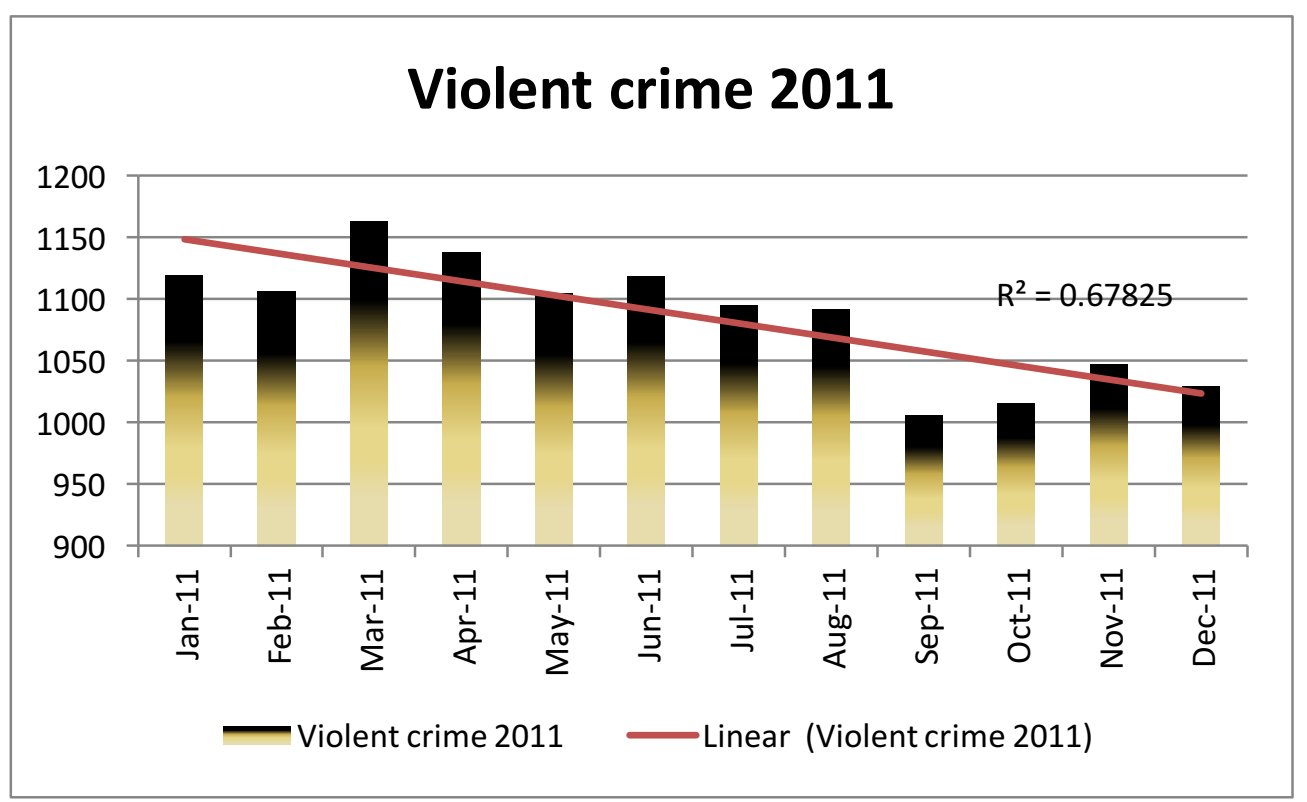

Mean $=1086.25$, standard deviation $=50.07$

Figure 5 monthly pattern violent crimes; source (South Yorkshire Police, 2011)

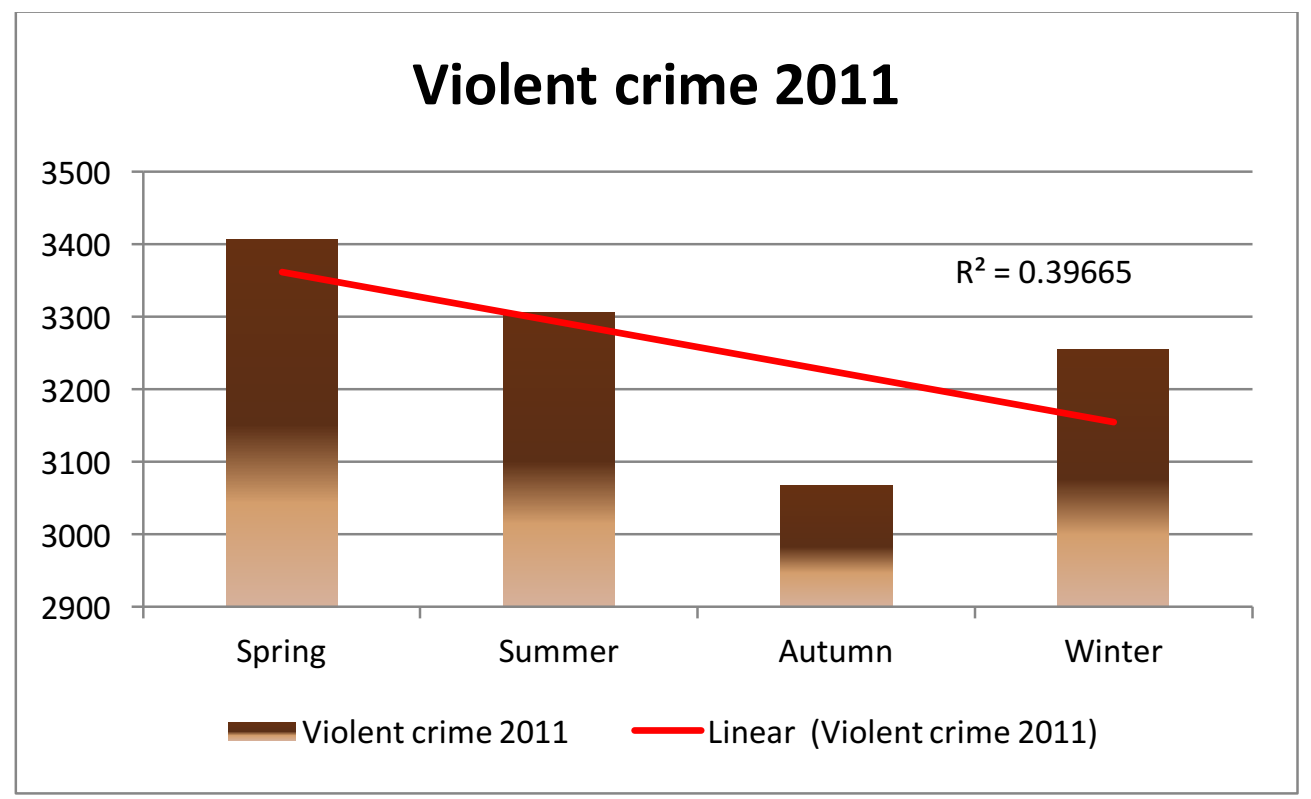

Mean $=3256.75$ standard deviation $=141.23$

Figure 6 seasonal pattern of violent crime, source (South Yorkshire police)

Both seasonal and monthly pattern of violent crime are displayed in figure 5 and 6 show March and spring depict the highest rates while September and autumn display the lowest rates. An interesting pattern in violent crime hot spot is shown in figure 5 , as $\mathrm{R}^{2}$ value of 0.67 , which indicates strong positive relationships between the months of the year while $\mathrm{R}^{2}$ value of 0.3967 in figure 6 shows weak correlations in seasonal trend of violent crime.

\section{DISCUSSION}

Visual inspection from the temporal pattern of crime hot spots for each crime type (figure 1 to 6) indicates correlation between crime seasons or months of the year. Numerous models of environmental criminologists such as routine activity and crime pattern theory (Santos, (11) support the link between crime and season. Evidence from the study (figure 2) shows that summer, 2011 had the highest rates while winter has the lowest incidents of ASB.During 
summer people to go for more outdoor activities (holidays and other leisure activities) which increase interaction between people and thus enhance opportunity for committing ASB .crime occurs where opportunity exist (Santos,(11).Result of the current research that weather affect ASB is consistent with the findings of Cohen (3) that support the link between crime occurrence and weather.

Evidence from the study discloses that violent crime has strong relationship with weather as Autum 2011 had highest incidents of violent crime while spring has lowest rates (see figure 5 and 6) also monthly trend indicates that March,2011 has the highest rates while September,2011 has the lowest rates of violent crime. The finding of the current study challenges this result of LeBeau (8) which states that rates violent crime were higher in summer and lower in winter.

January and autumn 2011 present highest incidents of vehicle crime while the lowest rates were displayed in April and summer 2011 (figure 3-4). In the UK, ,January is associated with bad weather (snow, longer hours of darkness, shorter days and longer nights) which could be one of the contributing factors for higher rates of vehicle crime as people with poor sight could have some driving challenges and hence improving opportunity for committing crime as described by theory of crime pattern and routine activity theory (Santos,(11).

\section{References}

BRUNSDON, Chris, CORCORAN, Jonathan and HIGGS, Gary (2007). Visualising space and time in crime patterns: A comparison of methods. Computers, environment and urban systems, 31 (1), 52-75.

CHAINEY, S. and RATCLIFFE, J. (2005). GIS and crime mapping. Wil ley.

COHN, E. G. (1990). Weather and crime. British Journal of criminology, 30 (1), 51-64.

ECK,J.,CHAINEY,S,.CAMERON,J and WILSON,R. (2005). Mapping crime: Understanding hotspots.

EVANS, D. J. and FLETCHER, M. (2000). Fear of crime: Testing alternative hypotheses. Applied geography, 20 (4), 395-411.

HARRIES, K. (2006). Extreme spatial variations in crime density in Baltimore county, MD. Geoforum, 37 (3), 404416.

LEBEAU, J. L. (2001). 7 mapping out hazardous space for police work1, 2. Mapping and analysing crime data: Lessons from research and practice, 139.

NELSON, A. L., BROMLEY, R. D. F. and THOMAS, C. J. (2001). Identifying micro-spatial and temporal patterns of violent crime and disorder in the British city centre. Applied geography, 21 (3), 249-274.

RATCLIFFE, J. (2010) Crime mapping: Spatial and temporal challenges. Handbook of quantitative criminology, , 524.

SANTOS, R. B. (2012). Crime analysis with crime mapping. Sage Publications, Incorporated.

South Yorkshire Police (2011). Police crime data. [online]. Last accessed 30th October 2012 at: http://www.police.uk/data.

TAKAGI, D, IKEDA, Ken'ichi and KAWACHI, Ichiro (2012). Neighborhood social capital and crime victimization: Comparison of spatial regression analysis and hierarchical regression analysis. Social science \& medicine, 75 (10), 1895-1902. 